NBER WORKING PAPER SERIES

\title{
HEALTH INSURANCE AND EX ANTE MORAL HAZARD: EVIDENCE FROM MEDICARE
}

\author{
Dhaval Dave \\ Robert Kaestner \\ Working Paper 12764 \\ http://www.nber.org/papers/w12764
NATIONAL BUREAU OF ECONOMIC RESEARCH
1050 Massachusetts Avenue
Cambridge, MA 02138

December 2006

The authors thank Karen Conway, Lorens Helmchen, Donald Kenkel, KerryAnne McGeary, Mark Pauly, and two anonymous referees, and seminar participants at the University of Illinois at Chicago, University of Chicago, Lafayette College, University of New Hampshire, and NBER for helpful suggestions. The views expressed herein are those of the author(s) and do not necessarily reflect the views of the National Bureau of Economic Research.

(C) 2006 by Dhaval Dave and Robert Kaestner. All rights reserved. Short sections of text, not to exceed two paragraphs, may be quoted without explicit permission provided that full credit, including $\bigcirc$ notice, is given to the source. 
Health Insurance and Ex Ante Moral Hazard: Evidence from Medicare

Dhaval Dave and Robert Kaestner

NBER Working Paper No. 12764

December 2006, Revised November 2009

JEL No. I12,I18

\begin{abstract}
$\underline{\text { ABSTRACT }}$
Basic economic theory suggests that health insurance coverage may cause a reduction in prevention activities, but empirical studies have yet to provide much evidence to support this prediction. However, in other insurance contexts that involve adverse health events, evidence of ex ante moral hazard is more consistent. In this paper, we extend the analysis of the effect of health insurance on health behaviors by allowing for the possibility that health insurance has a direct (ex ante moral hazard) and indirect effect on health behaviors. The indirect effect works through changes in health promotion information and the probability of illness that may be a byproduct of insurance-induced greater contact with medical professionals. We identify these two effects and in doing so identify the pure ex ante moral hazard effect. This study exploits the plausibly exogenous variation in health insurance as a result of obtaining Medicare coverage at age 65 . We find evidence that obtaining health insurance reduces prevention and increases unhealthy behaviors among elderly men. We also find evidence that physician counseling is successful in changing health behaviors.
\end{abstract}

\author{
Dhaval Dave \\ Bentley University \\ Department of Economics \\ 175 Forest Street, AAC 195 \\ Waltham, MA 02452-4705 \\ and NBER \\ ddave@bentley.edu \\ Robert Kaestner \\ Institute of Government and Public Affairs \\ University of Illinois \\ 815 West Van Buren Street, Suite 525 \\ Chicago, IL 60607 \\ and NBER \\ kaestner@uic.edu
}


Ms. Brooks said they dropped their health coverage in July after the family premium jumped to $\$ 989$ a month from $\$ 489$ a month. Business was slow, and their previous income of $\$ 60,000$ a year had fallen in half. The effect was immediate. Mr. Brooks, 50, has stopped taking Lipitor to control high cholesterol and has started taking over-the-counter herbal supplements. Ms. Brooks no longer takes Singulair for asthma and has adopted an exercise program intended to regulate her breathing. Ms. Brooks estimates they are saving $\$ 150$ a month by not using prescription drugs. "We changed our diets a lot to help the effectiveness of the supplements, and maybe that's a good thing," she said. ${ }^{1}$

This vignette from the New York Times is a perfect illustration of ex ante moral hazard - in this case, the loss of health insurance resulted in changes in health behavior that reduced the risk or severity of illness. While ex ante moral hazard is nearly always mentioned as a potential consequence of health insurance, it is equally as often noted that ex ante moral hazard is unlikely to be a significant problem.

"The extent of moral hazard in terms of actions that affect health may not be large for health insurance in most instances, since the uncompensated loss of health itself is so consequential." (Cutler and Zeckhauser 2000, p. 577)

"In the context of health insurance, the ex ante moral hazard problem may be small because common forms of health insurance in fact offer very incomplete coverage. Even if the consumer has generous coverage for the monetary components of the loss (medical expenditures and foregone earnings), he will be uninsured for the utility loss." (Kenkel, 2000, p.1687)

While limited, empirical evidence on the extent of ex ante moral hazard in the health insurance context is mostly consistent with these predictions about its importance (Kenkel 2000; Zweifel and Manning 2000). Findings from the Rand Health Insurance Experiment (RHIE) showed that less generous health insurance had no significant or practical effect on health behaviors such as smoking, drinking, and exercise (Newhouse 1993). Less generous insurance was associated with decreased use of preventive medical services (secondary prevention), which contradicts the simple intuition that less insurance should cause an increase in prevention (Lillard

\footnotetext{
${ }^{1}$ Broder, John. "Problem of Lost Health Benefits is Reaching into the Middle Class." New York Times November $25,2002$.
} 
et al. 1986). However, this finding is not conclusive because the consumer may engage in more primary prevention activities (self-protection) in response to an increase in the price of preventive medical care. Moreover, it is likely that the less generous (i.e., more cost-sharing) insurance plans in the RHIE increased the cost of preventive care relative to curative care due to the cap on out-of-pocket expenditures, and because these types of care are substitutes, consumers may have substituted toward curative care.

More direct evidence also offers mixed support for the ex ante moral hazard hypothesis. Courbage and Coulon (2004) found no evidence that private health insurance coverage reduced prevention (smoking and exercise) activities among British Households. In contrast, Klick and Stratman (2007) found that state mandated health insurance coverage for the treatment of diabetes, which is linked to obesity, was associated with higher body mass index among diabetics.

Empirical evidence in other insurance contexts is more supportive of the existence of a substantial amount of ex ante moral hazard. In the case of automobile insurance, there appears to be a significant reduction in prevention and an increase in accidents when the generosity of insurance is increased (Chiappori 2000). Indeed, Cohen and Dehejia (2004) examined the effect of compulsory auto insurance laws and found that having auto insurance was associated with an increase in auto fatalities. Similarly, in the workers' compensation (WC) case, increases in benefits (insurance generosity) are associated with more workplace injuries (Ruser 1985; 1991; Fortin and Lanoie 2000). The positive association between WC benefits and injuries is evidence that the worker moral hazard effect—less precaution because of more generous insuranceoutweighs the countervailing incentive for firms to increase safety investments to offset higher 
benefit (insurance) costs. Kaestner and Carroll (1997) empirically identify these two separate effects and reported a significant worker (ex ante) moral hazard effect.

It is interesting to note that the same rationale for why ex ante moral hazard may not be important in the health insurance context — that it is not possible to insure health-fails to explain findings in two other contexts that also involve adverse health effects. The consequences of reduced prevention in driving (automobile insurance) and at work (workers' compensation insurance) result in immediate and sometimes quite severe adverse health events. In comparison, a poor diet and smoking will not adversely affect health for many years, which lowers the cost of these behaviors (i.e., lowers the benefit of prevention). Furthermore, the costs of future adverse health events are low because all elderly persons are covered by Medicare. ${ }^{2}$

In sum, there are theoretical reasons to believe that health insurance coverage may cause a reduction in prevention activities, but empirical studies have yet to provide sufficient evidence to support this prediction. One explanation for the lack of empirical evidence is that it is more difficult to detect ex ante moral hazard in the health insurance context than in others because of the non-random nature of health insurance. Besides the RHIE, there have been relatively few exogenous sources of variation in health insurance that could be used to identify an ex ante moral hazard effect. Similar problems have plagued the study of the effect of health insurance coverage on other outcomes such as health and use of health care services (Brown et al. 1998; Levy and Meltzer 2004).

One source of plausibly exogenous variation in health insurance coverage is the introduction and expansion of public health insurance. The introduction of Medicaid and

\footnotetext{
${ }^{2}$ Kenkel (2000) suggests that another impediment to reducing prevention is that prevention decisions depend on having health insurance coverage at the time of the health loss and that movement in and out of insurance reduces the incentive to alter prevention activities. But this argument ignores the fact that in the US all persons age 65 and older are insured and this is the likely time of health loss from reduced prevention activities when younger.
} 
Medicare and the expansion of Medicaid have been used to study the effect of insurance on health care utilization and health (Decker 2005; Currie and Gruber 1996; Kaestner et al. 2000, 2001). However, this source of variation has been used only sparingly to study the effect of health insurance on prevention and health behaviors. Card et al. (2005) study the effect of obtaining Medicare at age 65 on several health behaviors and the use of preventive services. They find that obtaining insurance is not associated with changes in smoking, exercise and weight, nor is it strongly associated with use of preventive services (mammogram). In contrast, McWilliams et al. (2003) and Decker et al. (2006) find that obtaining Medicare at age 65 significantly increases rates of mammography, prostate and cholesterol screening. All of these results are evidence inconsistent with a strong, ex ante moral hazard effect.

In this paper, we extend the analysis of the effect of health insurance on health behaviors by examining the effect of Medicare on health behaviors of the elderly. Focusing on the elderly is useful because of the exogeneity of Medicare, but also because the benefits of prevention are more immediate among the elderly and prevention, particularly better health behaviors, may be more salient. The National Institute of Aging (NIA) reports that quitting smoking has immediate and important health benefits including a significantly lower risk of heart attack, stroke, other circulatory diseases and lung cancer. ${ }^{3}$ NIA also reports that staying physically active and exercising regularly can help prevent or delay many diseases and disabilities among the elderly.

We extend the literature on ex ante moral hazard by allowing for the possibility that health insurance, in this case Medicare, has a direct (ex ante moral hazard) and indirect effect on health behaviors. The indirect effect works through changes in health promotion information and the probability of illness that may be a byproduct of insurance-induced greater contact with medical professionals. There is significant evidence that physician counseling is successful in

\footnotetext{
${ }^{3}$ See http://www.niapublications.org/agepages/smoking.asp.
} 
changing health behaviors (Kenkel 2000; US Preventive Services Task Force 2003, 2004;

Viscusi 1995). Thus, obtaining insurance coverage at age 65 has two potentially offsetting effects on prevention. On the one hand, obtaining health insurance should reduce prevention because it lowers the cost of medical care (ex ante moral hazard). However, increased contact with physicians may alter information about the benefits of prevention and the probability of illness, which may increase prevention. We identify these two effects and in doing so identify the pure ex ante moral hazard effect. In contrast to most previous analyses, we find that obtaining health insurance does reduce prevention and increase unhealthy behaviors among elderly men. However, this finding is only apparent once we control for contact with medical professionals.

\section{Health Insurance, Information and Prevention}

The theoretical motivation for our study is a straightforward application of the Ehrlich and Becker (1972) model of the demand for self-protection (prevention). Following directly from Becker and Ehrlich (1972), the consumer's expected utility depends on income (I) in the healthy (1) and sick (0) state:

(1) $E U=[1-\pi(r)] U\left(I_{1}-r\right)+\pi(r) U\left(I_{0}-r\right)$,

where $r$ is the amount of money spent to reduce the probability of becoming sick (i.e., prevention). Maximizing consumer utility with respect to $r$ yields the first order condition [FOC(r)]:

$$
\begin{aligned}
F O C(r)= & -\frac{\partial \pi}{\partial r} U_{1}-[1-\pi(r)] U_{1}^{\prime}+\frac{\partial \pi}{\partial r} U_{0}-\pi(r) U_{0}^{\prime}=0 \\
& -\frac{\partial \pi}{\partial r}\left(U_{1}-U_{0}\right)=U_{1}^{\prime}+\pi\left(U_{0}^{\prime}-U_{1}^{\prime}\right)
\end{aligned} .
$$

Equation (2) is the usual marginal benefit equal to marginal cost equilibrium condition. The benefit of prevention is the increase in utility resulting from the decline in the probability of becoming ill; income in the healthy state is higher than income in the sick state so a decrease in 
the probability of becoming sick increases utility. The cost of prevention is the reduction in utility as a result of expenditures on prevention.

We now introduce health insurance into the analysis, but in a way that is intended to illustrate the effect of Medicare on behaviors. Specifically, we assume that there is no insurance prior to age 65 and at age 65 the consumer is given health insurance (q) that is free (i.e., Medicare). Thus, health insurance coverage depends only on age and it is exogenous. For an elderly (age > 64) consumer, Medicare changes expected utility as follows:

(3) $E U=[1-\pi(r)] U\left(I_{1}-r\right)+\pi(r) U\left(I_{0}-r+q\right)$.

Maximizing (3) with respect to prevention (r) also yields equation (2). Ex ante moral hazard arises because health insurance reduces the income difference between the healthy and sick states and therefore reduces the benefits of investment in prevention. A consumer who is fully insured $\left(\mathrm{q}=\mathrm{I}_{1}-\mathrm{I}_{0}\right)$ would receive no benefits from prevention and therefore not invest in prevention. $^{4}$

As equation (2) indicates, consumer prevention efforts depend on the productivity of prevention $\left(\frac{\partial \pi}{\partial r}\right)$ and the probability of illness $(\pi)$. Insurance may affect both of these determinants. Specifically, insurance is associated with an increase in physician visits and this increase in physician contact may influence prevention activities. Numerous studies have shown that physician advice and interventions are successful in influencing patient behaviors (US

\footnotetext{
${ }^{4}$ If health insurance premiums reflected the reduced level of risk caused by prevention, then even a consumer who is fully insured would invest in prevention (Ehrlich and Becker 1972). If the consumer is less than fully insured, increases in insurance may not necessarily reduce prevention, as insurance reduces both the marginal benefits and marginal costs of prevention (Ehrlich and Becker 1972). Ceteris paribus, insurance reduces prevention if the individual is sufficiently risk tolerant or if the marginal product of prevention efforts is sufficiently large.
} 
Preventive Services Task Force 2003, 2004). These studies have analyzed several lifestyle changes relating to problem drinking, smoking cessation, diet, and exercise. ${ }^{5}$

The evidence on the effects of physician counseling suggests that physicians alter the productivity of prevention because the physician may suggest more effective prevention strategies or provide better information about the benefits of a given prevention strategy. Similarly, contact with a physician may change the perception of illness; for example, physician contact may uncover a previously unknown illness. We can incorporate these ideas into the analysis by making the marginal product of prevention effort and the probability of illness a function of physician contacts (m), which itself is a function of insurance (q):

$$
\text { (4) } \begin{aligned}
m & =m(q) \\
\pi & =\pi[r, m(q)] . \\
\frac{\partial \pi}{\partial r} & =\frac{\partial \pi}{\partial r}[m(q)]
\end{aligned}
$$

Equation (2) then becomes:

(5) $\operatorname{FOC}(r)=-\frac{\partial \pi}{\partial r}[m(q)]\left(U_{1}-U_{0}\right)-\{1-\pi[r, m(q)]\} U_{1}^{\prime}-\pi[r, m(q)] U^{\prime}{ }_{0}=0$.

The effect of (exogenous) insurance (q) on prevention (r) is given by:

(6) $\frac{d r}{d q}=-\frac{\partial F O C(r)}{\partial q} / \operatorname{SOC}(r)$,

\footnotetext{
${ }^{5}$ Mundt et al. (2005) test the effectiveness of brief physician advice on reducing alcohol use among adults age 65 or older. The results of this clinical trial show that this physician intervention significantly reduced alcohol use and frequency of excessive drinking of the treatment group relative to the control group. Whitlock et al. (2004) review several intervention studies and conclude that brief intervention counseling or advice in a primary care setting can reduce weekly drinking by 13-34 percent. Other experimental (clinical trials) studies show that physician advice also positively affects diet and exercise patterns of adults and elderly persons (Elley et al. 2003; Bull et al. 1998). The literature on physician counseling also finds strong effects on smoking behaviors (Doescher and Saver 2000; Young and Ward 1998; Frank et al. 1991). Lancaster and Stead (2004) review 39 trials conducted between 1972 and 2003, to assess the effectiveness of physician-based advice related to smoking cessation. They conclude that even brief advice leads to a significant increase in the odds of quitting (odds ratio 1.69), with more intensive advice raising the likelihood of quitting even further.
} 
where $\mathrm{SOC}(\mathrm{r})$ is the second order condition with respect to $\mathrm{r}$, which is negative by assumption.

Thus, the sign of the effect of insurance on prevention is the same as the sign of $\frac{\partial F O C(r)}{\partial q}$ in equation (6), which is:

(7) $\frac{\partial F O C(r)}{\partial q}=-\frac{(\partial \pi)^{2}}{\partial r \partial m} \frac{\partial m}{\partial q}\left(U_{1}-U_{0}\right)+\frac{\partial \pi}{\partial r}\left[U^{\prime} 0\right]-\frac{\partial \pi}{\partial m} \frac{\partial m}{\partial q}\left(U^{\prime}{ }_{0}-U^{\prime}{ }_{1}\right)-\pi[r, m(q)] U^{\prime \prime} 0$.

We assume that physicians raise the marginal product of prevention $\left[\frac{(\partial \pi)^{2}}{\partial r \partial m}<0\right]$ and that physicians' effect on the probability (perception) of illness is ambiguous $\left(\frac{\partial \pi}{\partial m} \leq 0\right)$. Thus, the first term on the right hand side of equation (7) is positive, which indicates that insurance increases prevention because physician contacts improve the productivity of investments in prevention. The second term is negative and is the pure ex ante moral hazard effect-insurance reduces the value of investments in prevention because it raises income in the sick state. The third term may be positive or negative and depends on whether physician visits reveal that a person is healthier or sicker than expected. The last term is positive-prevention is increased because insurance lowers the marginal cost of prevention by providing more income in the sick state.

To summarize, empirical analyses of the effect of health insurance on health behaviors (ex ante moral hazard) need to account for changes in a person's information set that may occur as a result of insurance, most notably changes in information that are likely to occur because of greater receipt of medical services. It is well known that health insurance increases use of medical services (Newhouse 1993). Similarly, there is significant evidence that physicians are successful at changing lifestyle behaviors. So, insurance may reduce prevention because of traditional arguments related to ex ante moral hazard, but investigations of this effect may not 
uncover this behavior because of potentially offsetting effects caused by greater interaction with the medical system. Here, we separate out these two effects in the context of elderly persons who obtain insurance through Medicare.

\section{Methods}

Our objective is to identify the effect of Medicare on health behaviors. To accomplish this goal we used longitudinal data from the Health and Retirement Study (HRS) that allows us to observe persons before and after age 65 . We compare pre- to post-age 65 (Medicare) changes in behaviors (Y) of those who were uninsured before age 65 to pre- to post-age 65 changes in behaviors of those who were insured prior to age 65 . This is the approach used by McWilliams et al. (2003) and Decker et al. (2006). Specifically, we estimate the following regression model:

$$
\begin{aligned}
& Y_{i t}=\alpha_{i}+\sum_{k=60}^{69} \beta_{k} A G E_{k i t}+\delta M A R I T A L_{i t}+\omega X_{i t}+\sum_{t=1992}^{2006} \gamma_{t} Y E A R_{t}+\lambda_{1}\left(\text { UNIN }_{i} *{\left.\operatorname{POST~} 65_{k t}\right)}\right) \\
& i=1, \ldots, N \\
& t=1992, \ldots, 2006
\end{aligned}
$$

where $\mathrm{Y}$ is a measure of some health behavior, for example cigarette use, of person $\mathrm{i}$ in year $\mathrm{t}$; AGE is a series of dummy variables indicating single years of age (60 to 69); MARITAL is a dummy variable indicating that the person is married; $\mathrm{X}$ represents a vector or other time-varying individual characteristics and YEAR is a series of year dummy variables (1992 to 2006). Importantly, equation (8) includes individual fixed effects $\left(\alpha_{\mathrm{i}}\right)$ that control for time-invariant characteristics of individuals that may be correlated with health behaviors and health insurance coverage prior to age 65 . While receipt of Medicare at age 65 is exogenous, having health insurance prior to age 65 is a choice. Here we assume that this choice depends solely on a fixed, personal characteristic, conditional on other observed time-varying factors such as employment, and that once we control for this factor, insurance status prior to age 65 is exogenous. 
The key independent variable in equation (8) is the interaction term between a dummy variable indicating that the person was uninsured prior to age 65 (UNIN) and a dummy variable indicating that the person is over age 65 (POST65). The coefficient on this variable measures the effect of Medicare on health behaviors and this effect is identified in a difference-indifferences (DD) framework; the "treatment" group is persons who were uninsured prior to age 65 and the "comparison" group is persons who were insured prior to age 65 . Identification of the effect of Medicare comes from the assumption that, conditional on measured covariates, pre- and post-age 65 changes in health behaviors would be the same for the treatment and comparison groups in the absence of Medicare.

To assess the validity of this identification assumption, we also include an interaction between the uninsured dummy variable and a dummy variable for ages 63 to 64 . Ideally, the coefficient on this term would be zero - there would be no pre-age 65 differences in the time (age) pattern of outcomes between the insured and uninsured. In fact, we find this to be the case in most analyses. The coefficient of this interaction $\left(\lambda_{2}\right)$ is generally insignificant and close to zero, which supports the above identification assumption of similar trends between the two groups prior to age $65 .^{6}$ However, we also calculate (and present) the difference between $\lambda_{1}$ and $\lambda_{2}$. This is the difference-in-difference-in-differences (DDD) estimate and it is an alternative estimate of the ex ante moral hazard effect. It would be preferred to the difference-in-difference estimate if the interaction between the uninsured dummy variable and a dummy variable for ages 63 to 64 controlled for any differential trends between individuals who are insured versus uninsured.

\footnotetext{
${ }^{6}$ If there are anticipatory effects of Medicare, then including the interaction between uninsured and age 63 to 64 dummy would not be a good test of the identification assumption. Generally, we do not find any significant effects, which is consistent with no anticipatory changes. Card et al. (2008) also do not find evidence of significant anticipatory behavior.
} 
We have raised the possibility that Medicare coverage will also affect health behaviors indirectly because of greater contact with medical professionals. Indeed, it is well known that insurance increases physician visits and use of other medical services. It is also known that physician visits affect health behaviors. To incorporate these ideas, we modify equation (8) to include physician visits:

$$
\begin{aligned}
& Y_{i t}=\alpha_{i}+\sum_{k=60}^{69} \beta_{k} A G E_{k i t}+\delta M A R I T A L_{t}+\sum_{k=1}^{K} \omega_{k} X_{k i t}+\sum_{t=1992}^{2006} \gamma_{t} \text { YEAR }_{t}+\lambda_{1}\left(\text { UNIN }_{i} * \text { POST65 }_{k t}\right) \\
& +\lambda_{2}\left(\text { UNIN }_{i} * A G E 63 \_64_{k t}\right)+\rho_{1} \text { DOCTOR }_{t t}+\rho_{2}\left(\text { DOCTOR }_{t t} * \text { POST65 }\right) \\
& +\rho_{3}\left(\operatorname{UNIN}_{i} * \operatorname{DOCTOR}_{t t}\right)+\rho_{4}\left(\operatorname{UNIN}_{i} * \operatorname{DOCTOR}_{t t} * \operatorname{POST65}_{t}\right)+e_{i t}
\end{aligned}
$$

where all variables are defined as before with the exception of DOCTOR, which measures whether person $i$ had a physician visit at time t. We allow the effects of physician visits on health behaviors to differ by whether or not a person had health insurance coverage prior to age 65 and whether the visit was pre- or post-Medicare.

We allow for heterogeneous effects of physician visits on health behaviors because there is a missing variable, health status, which is likely correlated with both doctor visits and health behaviors. Therefore, estimates of the effect of doctor visits are likely to be biased, particularly for doctor visits pre-Medicare for those without insurance because poor health is likely to be the motivating force behind the decision to seek care. As a result, the coefficients $\rho_{1}, \rho_{2}$, and $\rho_{4}$ will be better measures of the effect of physician visits on health behaviors than $\rho_{3}$.

Identification of the ex ante moral hazard effect comes from two assumptions: that health status is uncorrelated with the interaction between uninsured and the post-age 65 dummy (conditional on individual fixed effects and observed covariates), and that the ex ante moral hazard effect of Medicare is the same for those who did not visit the doctor pre- and postMedicare and those that did visit the doctor. 


\section{Data}

The empirical analysis is based on the first eight waves of the Health and Retirement Study (HRS). The HRS is an ongoing longitudinal study conducted by the Institute for Social Research at the University of Michigan, which began in 1992 and is repeated biennially. We used surveys through 2006. Prior to 1998, the HRS cohort included individuals born between 1931 and 1941 and their spouses regardless of the spouse's age, and a separate Study of Assets and Health Dynamics among the Oldest Old (AHEAD) included individuals born before 1924. Since 1998, AHEAD respondents have been contacted as part of a joint data collection effort with the HRS, and the sample frame was also expanded by including cohorts born between 1924 and 1930 and those born between 1942 and 1947. The analysis sample is limited to individuals who are between the ages of 60 and 69 , in order to provide a tighter comparison pre- and postMedicare age eligibility. Disabled persons and those on Medicare prior to age 65 are excluded from the analysis. The sample is further restricted to adults who have not completed high school because of the relatively high rate of uninsured persons in this group. About 24 percent of individuals between the ages of 60 and 64 with less than a high school education are uninsured whereas 8.7 percent of those with at least a high school degree are uninsured. This low-educated group also has a higher participation in unhealthy behaviors such as smoking and physical inactivity relative to the general population. Thus, the question of how health insurance affects health behaviors among the low-educated is relevant to informing policies that seek to reduce the number of uninsured. ${ }^{7}$ The final sample size across eight waves comprises of 9,782 person-wave observations for 3,396 persons. $^{8}$

\footnotetext{
${ }^{7}$ We have also estimated all models using persons of all education levels and the results were basically unchanged.

${ }^{8}$ This is the maximum sample size in the analyses. For some variables, the actual sample size is less due to missing information.
} 
The HRS is administered for the specific purpose of studying life-cycle changes in health and economic resources, and includes detailed information on demographics (e.g., age, marital status, education, race), health insurance status, health care utilization, and health behaviors. The respondent's health insurance status is determined from a series of questions about the type of coverage. For each wave, a coverage indicator is defined for whether the individual reports being covered by health insurance under any governmental program including Medicare or Medicaid, under his own current or previous employer, under his spouse's current or previous employer, or under any other supplemental insurance. Two measures of uninsured are employed in the analysis. The first captures those individuals who have been continuously uninsured during all waves prior to age 65 , and the second measure captures those individuals who have been uninsured more than half the time prior to age 65 . About 11 percent of the analysis sample between the ages of 60-64 is uninsured in all waves, and 21 percent is uninsured more than half the time over the sample period.

Dichotomous indicators are defined for various dimensions of health care utilization. These measure whether the respondent reported any overnight hospital stay and any physician visit, since the prior wave. A continuous measure of the number of physician visits is also defined. To ensure a more precise classification of health care utilization pre- and post-age 65 , these variables are assigned to the respondent's mean age between the prior and the current wave. Thus, for a respondent who is currently 65 and reports a physician visit since the prior wave, the health care usage is appropriately treated as a pre-age 65 observation.

Three health behaviors are considered: exercise, smoking and alcohol use. Questions related to physical activity are somewhat limited. We measure exercise by a dichotomous indicator for whether the respondent reports participating in "vigorous physical activity or 
sports — such as heavy housework, aerobics, running, swimming, or bicycling — three or more times a week." Three measures of cigarette consumption are constructed: number of cigarettes smoked daily, dichotomous indicator of daily smoking, and a dichotomous indicator for whether the person quit smoking. The number of cigarettes smoked daily is taken directly from a survey question that asks respondents to report on the number of cigarettes or packs (20 cigarettes per pack) that they smoke each day. If a respondent reports a positive number, we consider them a daily smoker. While the number of days per week of smoking is not asked in the HRS, data from the Behavioral Risk Factor Surveillance System (BRFSS) show that the vast majority of current smokers (over 85 percent) smoke daily. As a consistency check, among adults ages 6064 with less than a high school education, the prevalence of daily smoking is highly similar across the HRS (26.4 percent) and the BRFSS (24.0 percent). Finally, we define an indicator for whether the respondent has quit smoking, which is equal to one if a person had smoked in the past, but currently doesn't smoke.

Alcohol use is measured as a dichotomous indicator for whether the respondent currently drinks. From waves 3-8, the HRS also asks respondents to report on the number of days that they consume alcohol during an average week. An indicator for daily drinking is defined based on this measure of frequency.

Table 1 provides descriptive statistics for respondents by insurance status (consistently uninsured in all waves). Samples are limited to respondents less than 65 years of age because we wanted to show pre-Medicare differences. Table 1 also provides information about the demographic variables used in the analysis: gender, age, race, marital status, and education. Figures in Table 1 show that the insured visit the doctor more frequently and are more likely to

\footnotetext{
${ }^{9}$ Due to an inconsistency in the survey questions in waves seven and eight, models of physical activity are estimated for the first six waves of the HRS.
} 
have a hospital visit than the uninsured. The insured also smoke less than the uninsured. There are no significant differences in exercise or alcohol use between the insured and uninsured.

\section{Results}

We begin by presenting estimates of the effect of Medicare on physician visits and hospital stays. Our intention here is to establish that Medicare is associated with a significant increase in visits to medical providers and that our results are similar to those of previous studies. Table 2 reports estimates of the effect of Medicare on whether a low-educated person had any doctor visits in the last two years, the number of doctor visits in the past two years and whether a person had a hospital stay in the past two years. We discuss the difference-in-difference-indifferences estimates (DDD), but these are very similar to the simpler difference-in-differences estimates (DD). For low-educated males who were always uninsured prior to age 65, receipt of Medicare:

- significantly increased the probability of seeing a doctor by 7.6 percentage points, which represents a 12.4 percent increase from the pre-age 65 mean of the uninsured;

- $\quad$ significantly increased the number of doctor visits by 30.9 percent; ${ }^{10}$

- $\quad$ and increased the probability of having a hospital stay by 4.8 percentage points $(32.2$ percent), although this effect is not statistically significant.

For low-educated females who were always uninsured prior to age 65, receipt of Medicare:

- increased the probability of seeing a doctor by an insignificant 2.7 percentage points ( 3.4 percent);

\footnotetext{
${ }^{10}$ We use fixed effects Poisson regression to estimate models for count outcomes: number of doctor visits and number of cigarettes consumed daily (reported later). The Poisson model does not suffer from the "incidental parameters" problem and can accommodate fixed effects well; both the conditional and unconditional likelihood maximization yield consistent and identical parameter estimates. The standard errors are adjusted for overdispersion as described in Wooldridge (2001). For all other dichotomous outcomes, OLS is used for estimation. Results are not sensitive to the use of logit/probit for these outcomes.
} 
- significantly increased the number of doctor visits by 38.8 percent;

- and increased the probability of having a hospital stay by an insignificant 3.2 percentage points (21.3 percent).

As can be seen in Table 2, results are similar if we focus on persons who were uninsured more than half the time prior to age 65 instead of those always uninsured. These results are also similar to those reported in recent studies. Estimates in Card et al. (2005) suggest that gaining Medicare coverage was associated with a 24 percentage point increase in the probability of visiting a doctor among white, non-Hispanic high-school drop outs (males and females), and a 23 percentage point increase among high-school drop outs from other race/ethnic groups. ${ }^{11}$ In the case of any hospital visit, estimates in Card et al. (2005) suggest that gaining Medicare was associated with a 12.3 percentage point increase in the probability of experiencing a hospital stay among non-Hispanic white drop outs, and Medicare was not associated with a hospital stay for drop outs of other race/ethnic groups. Decker et al. (2006), who use a similar methodology and the same data as us, found that receipt of Medicare increased the probability of a doctor visit by five percentage points among previously uninsured persons (males and females), and increased the probability of a hospital stay by 3.3 percentage points. ${ }^{12}$ Overall, the results we report and those in previous studies demonstrate that receipt of Medicare clearly increases contact with medical providers. It is this contact that we believe is an important confounding influence when trying to identify the ex ante moral hazard effect of insurance.

\footnotetext{
${ }^{11}$ These effects sizes were calculated by inflating the regression discontinuity (RD) estimates for doctor visits using the regression discontinuity estimates for any insurance coverage. For example, the RD estimate indicated that among non-Hispanic, white drop outs, the pre- to post-age 65 change in the probability of visiting a doctor was 3.1 percentage points. The RD estimate related to any insurance coverage was 13 percentage points. So the implied effect of Medicare was 23.9 percentage points $(0.031 / 0.13)$. It is important to note that estimates rescaled in this way can differ dramatically with relatively small changes in the underlying estimates.

${ }^{12}$ One reason our estimates are larger than those in Decker et al. (2006) is that we estimate separate models for males and females. In addition, we limit the sample to low-educated persons and do not restrict the sample to those individuals only observed in wave 1. Decker et al. (2006) also only utilize the first six waves of the HRS.
} 
Next, we examine the effect of receipt of Medicare on health behaviors: exercise, smoking and drinking. Table 3 reports estimates for the male sample. Here we focus on those who were always uninsured and Appendix Table 1 presents estimates for an alternative groupthose uninsured more than 50 percent of the time, which includes the always uninsured. Results in Appendix Table 1 are similar to those in Table 3. For each outcome, we report estimates from two models: one that does not control for doctor visits and one that does. Again, we discuss the DDD estimates only, but DD estimates are similar. More importantly, estimates indicate no statistically significant pre-age 65 trends, which supports the identification assumption underlying the analysis.

For exercise, receipt of Medicare is associated with a 9.1 percentage point (24 percent) decrease in the probability of engaging in vigorous physical activity. However, this estimate includes both the ex ante moral hazard effect and the effect of increased contact with physicians and other medical professionals. When we control for doctor visits, the main effect of Medicare receipt on exercise becomes larger (-15.1 percentage points or 40 percent). By main effect of Medicare, we refer to the effect of Medicare receipt for a previously uninsured person who did not visit the doctor pre- or post-Medicare receipt. This is the ex ante moral hazard effect, or $\left(\lambda_{1}\right.$ $\lambda_{2}$ ) of equation (9). Note that none of the coefficients on doctor visits are statistically significant or large. Similar results are reported in Appendix Table 1, which pertains to those uninsured at least half the time prior to age 65. Finally, we note that results (not reported) do not differ qualitatively if we use an alternative measure of exercise. The absence of a substantial effect of physician visits on exercise is consistent with evidence reviewed by the US Preventive Services 
Task Force (2002), which reported mixed evidence as to the effect of physician counseling on exercise and physical activity. ${ }^{13}$

The next outcome is cigarette consumption. In the absence of controls for doctor visits, receipt of Medicare is associated with a small (1.3 percent) and statistically insignificant decrease in the number of cigarettes smoked daily. When we control for doctor visits, receipt of Medicare is associated with a 22.7 percent increase in daily cigarette consumption among those who never visit a physician, and visits to the doctor have large effects on smoking. However, most of these estimates of physician effects, while large, are not statistically significant. Among the always insured group, a visit to the doctor is associated with an insignificant 10 percent decrease in daily cigarette consumption, and for those who were uninsured prior to age 65 , a visit to the doctor post-age 65 when they have Medicare is associated with a 42.1 percent decrease in daily cigarette consumption. These results are consistent with the simple theoretical model and empirical evidence about the effectiveness of physician visits in changing health behaviors. They reveal that Medicare is associated with an increase in unhealthy behavior (i.e., ex ante moral hazard) once we control for the effect of Medicare on doctor visits and that doctor visits are health promoting.

Similar results are found when we analyze whether a person quit smoking and whether they are a daily smoker. Among those who do not visit the doctor pre- or post-Medicare, Medicare receipt is associated with an 8.1 percentage point, or 18 percent, lower probability of quitting smoking and a 6.7 percentage point, or 15.8 percent, higher prevalence of daily smoking

\footnotetext{
${ }^{13}$ In contrast, Card et al. (2008), using data from the BRFSS find that Medicare is associated with a 36.1 percentage point (72 percent) increase in strenuous exercise among white, high school dropouts, and a 19.7 percentage point (22 percent) increase among non-white drop outs. Effect size was calculated as in footnote 11: dividing the RD estimate for exercise by the RD estimate for insurance coverage.
} 
once we adjust for the effect of contact with the medical profession. ${ }^{14}$ These are estimates of the ex ante moral hazard effect of Medicare. Physician visits are associated with a significant increase in the probability of quitting smoking and a significant decrease in daily cigarette consumption among the always insured, and a substantial, but not statistically significant increase in the probability of quitting smoking and decrease in daily cigarette consumption among those who gain Medicare. Similar estimates are reported in Appendix Table 1.

The last behavior we analyze is alcohol consumption, which we measure in two ways: dichotomous indicators for any alcohol use and daily consumption. Controlling for doctor visits, receipt of Medicare among the previously uninsured group is associated with an 11.6 percentage point (31.8 percent) increase in the probability of any alcohol consumption and a 2.0 percentage point (14.8 percent) increase in daily alcohol consumption. Neither estimate is statistically significant. However, consistent with our hypothesis, once we control for doctor visits, estimates of ex ante moral hazard are more consistent with theory-insurance causes an increase in unhealthy behaviors. Doctor visits tend to decrease alcohol use, especially among those who were uninsured prior to age 65. Estimates in Appendix Table 1 show a much smaller ex ante moral hazard effect and are generally less consistent with our hypotheses.

One challenge with our analysis is the evident lack of statistical power. In several cases, we found relatively large effects of obtaining Medicare on health behaviors, but these effects were not statistically significant. To address this issue, we did the following. First, we redefined the dichotomous dependent variables so that all of them represent unhealthy behaviors (i.e., no vigorous exercise, daily cigarette use, did not quit smoking, alcohol user, and daily alcohol use),

\footnotetext{
${ }^{14}$ Card et al. (2005) find a decrease in daily smoking among white, non-Hispanic dropouts and an increase in daily smoking among non-white high-school dropouts. Neither effect is statistically significant. However, given that few persons in either group are likely to be affected by Medicare (i.e., already insured), the implied effect sizes are quite large.
} 
and we transformed these dependent variables into standard normal deviates [(Y-mean)/std. dev.]. Transforming the dependent variables in this way allows us to obtain estimates of the effect of obtaining insurance on behaviors using a seemingly unrelated regression framework, and in turn allows us to test joint hypotheses across equations. All effects are measured as changes in standard normal deviations of the dependent variables and we test whether the average effect across models is statistically different from zero.

Table 4 presents these results. Here too, we focus on DDD estimates and all models include doctor visits. In each column, we present an estimate of the average effect of Medicare receipt on three unhealthy behaviors: no vigorous exercise, smoking, and alcohol use. The pvalue associated with the estimate is shown in brackets. We alternate the measures of smoking and alcohol use that are used in the regressions and these are indicated in the column headings. In all cases, we find that, after accounting with physician contact, on average Medicare increased unhealthy behaviors, consistent with ex ante moral hazard. For instance, the estimate in the first column indicates that receipt of Medicare is associated with a 0.234 of a standard deviation increase in unhealthy behaviors and this effect is statistically significant at the 0.01 level. In column two, we replace daily cigarette consumption with not quitting cigarette use, and the estimate is similar; receipt of Medicare is associated with a 0.241 of a standard deviation increase in unhealthy behaviors and this effect is statistically significant at the 0.01 level. In column three, we replace alcohol participation with daily alcohol use. The estimate indicates that receipt of Medicare is associated with a 0.178 of a standard deviation increase in unhealthy behaviors and this effect is statistically significant at the 0.14 level. Finally, in column four the three behaviors we used were: no vigorous exercise, not quit smoking, and daily alcohol use. The estimate in this column indicates that the receipt of Medicare is associated with a 0.184 of a 
standard deviation increase in unhealthy behaviors and this effect is statistically significant at the 0.13 level. We view the estimates in Table 4 as confirmatory of the general findings of Table 3 and as further evidence that Medicare is associated with an increase in unhealthy behaviors (net of doctor visits). Simultaneous estimation of all three outcomes improves the precision of estimates and allows us to draw more definitive inferences.

Table 5 presents estimates of the effect of Medicare on the health behaviors of elderly women. Here too, we present estimates of the effect of Medicare for those who were always uninsured prior to age 65. Estimates using an alternative definition of uninsured, more than half the time, are presented in Appendix Table 2 and are consistent with those discussed in the text. Before beginning, we note that Medicare receipt was not associated with large changes in contact with the medical profession for uninsured women (see Table 2). Thus, we do not expect physician visits to be a particularly important confounding factor for the relationship between receipt of health insurance and health behaviors.

In the case of exercise, Medicare is associated with a decrease in the probability of engaging in vigorous exercise, and after controlling for visits to the doctor, the main (i.e., ex ante moral hazard) effect increases in magnitude and is quite large. Receipt of Medicare for those with no pre- or post-age 65 doctor visits is associated with a 12.8 percentage point (43 percent) decrease in the probability of engaging in vigorous exercise, and among those uninsured prior to age 65, a doctor visit post-Medicare receipt is associated with an 11.9 percentage point increase in engaging in vigorous physical activity. However, both of these estimates are not statistically significant. Overall, Medicare appears to be associated with a decrease in physical activity, which is consistent with an ex ante moral hazard effect. 
Among elderly women, Medicare receipt is not associated with a strong ex ante moral hazard effect on smoking. In fact, Medicare receipt is associated with a large decrease (30.9 percent) in the number of cigarettes smoked per day. With respect to daily cigarette participation and quitting smoking, a small ex ante moral hazard effect emerges after controlling for physician contact. Among women who do not visit the doctor pre- or post-Medicare, Medicare receipt is associated with an 4.3 percentage point, or 7.7 percent, lower probability of quitting smoking and a 2.2 percentage point, or 9.6 percent, higher prevalence of daily smoking. Estimates in Table 5 and Appendix Table 2 provide some evidence that physicians have a beneficial effect on elderly female tobacco use. A visit to the doctor for someone who was always insured is associated with a statistically significant 8.8 percentage point (16 percent) increase in the probability of quitting smoking, and for a previously uninsured person, visiting the doctor post-receipt of Medicare is associated with a 10.3 percentage point (18 percent) increase in quitting. Estimates of the effects of physician visits of similar magnitude are found for daily cigarette consumption. The last set of estimates in Table 5 pertains to alcohol use. Here we find that receipt of Medicare is associated with a decrease in alcohol participation and an increase in daily alcohol consumption. Estimates are small in absolute value, but large in relative terms and estimates are not statistically significant.

In Table 6, we present estimates of the effect of obtaining insurance on behaviors using a seemingly unrelated regression framework. As noted, all effects are measured as changes in standard normal deviations of the dependent variables and we test whether the average effect across models is statistically different from zero. DDD estimates indicate that receipt of Medicare is associated with an increase in unhealthy behaviors on average. However, none of the estimates are statistically significant. 


\section{Sensitivity Analyses}

We conducted several additional analyses to assess the robustness of the previous findings. While all estimates were obtained controlling for time-invariant individual heterogeneity, the possibility of unobserved time-varying factors remains. Theory would suggest that health is one of the most important time-varying characteristic that may be driving an individual's health behaviors and doctor visits. To assess this possibility, we performed three analyses. First, we re-estimated all models including direct controls for health status.

Specifically, equation (9) was estimated by explicitly controlling for self-reported health status, functional difficulties, and difficulties in activities of daily living. Second, we exploited the longitudinal nature of the data to control for lagged doctor visits from the prior wave in the models. Finally, we included leading health indicators. The results from these analyses remain almost unchanged from previous estimates.

While all models control for employment indicators, we acknowledge that this may be potentially endogenous. Therefore, we also estimated models with and without employment and the results are not substantially affected with respect to significance or effect magnitudes. Finally, we also estimated models which constrain the effects of doctor visits to be the same preand post-age 65 for those who are always insured, as there is no a priori reason why these effects should likely differ. We found that we were unable to reject this restriction as expected, and the results are not affected in comparison with those reported.

In Appendix A, we obtain estimates of the impact of Medicare on health behaviors based on an alternate dataset (Behavioral Risk Factor Surveillance System) and an alternate crosssectional identification strategy. Similarity in the magnitudes and pattern of estimates is validating and raises the level of confidence in the analyses. 


\section{Conclusions}

Economic theory suggests that health insurance may reduce prevention because it lowers the cost of medical care and thereby reduces the financial and health consequences of illness. This implies that receipt of insurance will result in an increase in unhealthy behaviors like smoking and drinking. This is often referred to as ex ante moral hazard. However, previous research in the context of health insurance has not found much evidence of an ex ante moral hazard effect, which is surprising because in similar contexts, workers compensation insurance and automobile insurance, evidence of an ex ante moral hazard effect has been found.

We hypothesize that one possible explanation for this is that health insurance not only changes incentives related to prevention and health behavior, but also changes use of medical services and contact with medical professionals. These effects may be offsetting and the net effect of insurance on health behaviors may be positive or negative. More importantly, previous empirical research has not separated the direct (ex ante moral hazard) effect from the indirect effect (physician visits) of insurance on health behaviors. Here we do so.

We study the effects of receipt of Medicare on the health behavior of elderly persons. We used longitudinal data and difference-in-differences (and DDD) research design to obtain estimates of the effects of Medicare. Specifically, we compare changes in health behavior preand post-age 65 of those who are uninsured and those who are insured prior to age 65 . We expect the change in health behaviors of those who are uninsured prior to age 65 to differ from those who are insured, and we assume that this difference is the effect of Medicare. To identify the ex ante moral hazard effect, we estimate models that control for physician visits. 
The pattern of results shows consistent evidence of an ex ante moral hazard effect for males. Among elderly men, the ex ante moral hazard effects associated with receipt of Medicare are as follows:

- a 39.7 percent decrease in the probability of engaging in vigorous physical exercise;

- a 18.0 percent lower probability of quitting cigarette use;

- a 15.8 percent higher prevalence of daily smoking;

- a 22.7 percent higher cigarette consumption;

- a 14.8 percent increase in the probability of daily alcohol consumption;

- $\quad$ and a 31.8 percent increase in the probability of current alcohol use.

We did not find consistent evidence of an ex ante moral hazard effect for females, although estimates generally indicated that Medicare was associated with an increase in unhealthy behaviors.

These estimates provide evidence that Medicare (health insurance) is associated with less prevention as manifested by an increase in unhealthy behaviors among elderly males. The effect sizes appear to be large enough to adversely affect health. But evidence also suggests that Medicare was associated with an increase in visits to the doctor and that doctor visits are associated with significant improvements in health behaviors. Often these two effects associated with Medicare are sufficient to yield a combined effect that is small and usually not statistically different from zero. One policy implication of our findings is that Medicare should be designed to encourage visits to the doctor, particularly among those who were previously uninsured. This could be accomplished by removing co-payments and annual deductibles, and covering routine doctor visits, perhaps for low-income adults only. Greater community outreach would also 
expand contact between individuals in vulnerable populations (low SES and more likely to be uninsured) and medical professionals. 


\section{References}

Brown, M., A. B. Bindman and N. Lurie. 1998. "Monitoring the Consequences of Uninsurance: A Review of Methodologies." Medical Care Research and Review, 55(2): 177-210.

Bull, F.C. and K. Jamrozik. 1998. "Advice on exercise from a family physician can help sedentary patients to become active - a survey of US family practitioners." American Journal of Preventive Medicine, 15(2): 85-94.

Card, D., C. Dobkin and N. Maestas. 2005. "The Impact of Nearly Universal Insurance Coverage on Health Care Utilization and Health: Evidence from Medicare." Working Paper, University of California, Berkeley.

Chiappori, P.A. 2000. "Econometric Models of Insurance under Asymmetric Information", in G. Dionne, (eds.) Handbook of Insurance, North Holland.

Cohen, A. and Dehejia, R. 2004. "The Effect of Automobile Insurance and Accident Liability Laws on Traffic Fatalities." Journal of Law and Economics, 47(2): 357-393.

Courbage, C. and A. Coulon. 2004. "Prevention and Private Health Insurance in the U.K".

Geneva Papers on Risk and Insurance: Issues and Practice, 29(4): 719-727.

Currie, J. and J. Gruber. 1996. "Saving babies: The efficacy and cost of recent changes in the Medicaid eligibility of pregnant women." Journal of Political Economy, 104(6):1263 - 1296.

Cutler, D. M. and R. Zeckhauser. 2000. "Insurance markets and adverse selection", in A.J. Cutler and J. P. Newhouse, (eds.) Handbook of Health Economics, North Holland.

Decker, S. 2005. "Medicare and the Health of Women with Breast Cancer." The Journal of human resources,40(4): 948-968.

Decker, S., Dushi, I., and Deb, P. 2006. "Medicare at Age 65: Does it Level the Playing Field?" Unpublished manuscript

Doescher, M. P. and B. Saver. 2000. "Physicians' advice to quit smoking. The glass remains half empty." Journal of family practice, 49(6): 543-7.

Ehrlich, I. and G. Becker. 1972. "Market Insurance, Self-Insurance, and Self-Protection” Journal of Political Economy, 80(4): 623-48.

Elley, C.R., N. Keres, B. Arroll and E. Robinson. 2003. "Effectiveness of counselling patients on physical activity in general practice: cluster randomised controlled trial." British Medical Journal, 326: 793-799. 
Fleming M., K. L. Barry, L. B. Manwell, K. Johnson, and R. London. 1997. "Brief physician advice for problem alcohol drinkers. A randomized controlled trial in community-based primary care practices." The Journal of the American Medical Association, 277(13).

Fortin, B. and P. Lanoie, 2000. "Incentive Effects of Worker's Compensation : A Survey” ", in G. Dionne, (eds.) Handbook of Insurance, North Holland.

Frank E., M. Winkleby, D. Altman, B. Rockhill and S. Fortmann. 1991. "Predictors of physician's smoking cessation advice." Journal of the American Medical Association, 266(22): 3139-3144.

Goldstein, M. G., J. D. DePue, A. D. Monroe, C. W. Lessne, W. Rakowski, A. Prokhorov, R. Niaura, and C. E. Dubé. 1998. "A population-based survey of physician smoking cessation counseling practices," Preventive Medicine. 27(5):720-729.

Grandes, G, J. Cortada, and A. Arrazola. 2000. "An evidence-based programme for smoking cessation: effectiveness in routine general practice." British Journal of General Practice, 50: 803:807.

Kaestner, R. and A. Carroll. 1997. 'New Estimates of the Labor Market Effects of Workers' Compensation Insurance.” Southern Economic Journal, 63(3):635-651.

Kaestner, Robert, Theodore Joyce and Andrew Racine. 2001. "Medicaid Eligibility and the Incidence of Ambulatory Care Sensitive Hospitalizations for Children." Social Science and Medicine 52: 305-313.

Kaestner, Robert, Andrew Racine and Theodore Joyce. 2000. "Did Recent Expansions in Medicaid Narrow Socioeconomic Differences in Hospitalization Rates of Infants? Medical Care 38(2): 195-206.

Kenkel, D. S. 2000. "Prevention", in A. J. Culyer and J. P. Newhouse, (eds.) Handbook of Health Economics, North Holland.

Klick, J. and T. Stratmann. 2004. "Diabetes Treatments and Moral Hazard” . FSU College of Law, Law and Economics Paper No. 05-21 Available at SSRN: http://ssrn.com/abstract=766825.

Kreuter, M. W., N. Lezin and L. Young. 2000. "Evaluating Community-based Collaborative Mechanisms, Implications for Practitioners.” Health Promotion Practice, 1(1): 49-63.

Lancaster T. and L. Stead. 2004. "Physician advice for smoking cessation." Cochrane Database System Review, 18(4): CD000165.

Levy, H. and D. Meltzer. 2004. "What do we Really Know about how Health Insurance Affects Health?" in C. McLaughlin, (eds.) Health Policy and the Uninsured, Urban Institute Press. 
Lilliard LA, W. G. Manning, C. E. Peterson, N. Lurie, G. Goldberg and C. E. Phelps. 1986. Preventive Medical Care: Standards, Usage and Efficacy. Santa Monica, CA: Rand Publication Services, Report No. R3266-HCFA.

McWilliams, M., A. M. Zaslavsky, E. Meara and J. Ayanian. 2003. "Impact of Medicare Coverage on Basic Clinical Services for Previously Uninsured Adults" Journal of the American Medical Association. 290:757-764.

Mundt, P., T. French, C. Roebuck, B. Manwell and L. Barry. 2005. "Brief physician advice for problem drinking among older adults: An economic analysis of costs and benefits." Journal of studies on alcohol, 66(3): 389-394.

Newhouse, J. P. 1993. "Free for all? Lessons from the RAND Health Insurance Experiment." A RAND Study, Cambridge and London, Harvard University Press.

Ossip-Klein J., S. McIntosh, C. Utman, K. Burton, J. Spada and J. J. Guido. 2000. "Smokers ages 50+: Who gets physician advice to quit?" Preventive Medicine, 31:364-369.

Ruser, John W. 1985. "Workers' Compensation Insurance, Experience-rating, and Occupational Injuries” RAND Journal of Economics, 16(4): 487-503.

Ruser, John W. 1991. "Workers' Compensation and Occupational Injuries and Illnesses", Journal of Labor Economics 9(4): 325-50.

US Preventive Services Task Forces (PSTF). 2002. "Behavioral Counseling to Promote Physical Activity." Report of the US Preventive Services Task Force, US Department of Health and Human Services.

US Preventive Services Task Forces (PSTF). 2003. "Counseling for a Healthy Diet.” Report of the US Preventive Services Task Force, US Department of Health and Human Services.

US Preventive Services Task Forces (PSTF). 2004. "Screening and Behavioral Counseling Interventions in Primary Care to Reduce Alcohol Misuse." Report of the US Preventive Services Task Force, US Department of Health and Human Services.

Viscusi, W. 1995. "Discounting Health Effects for Medical Decisions," in Frank Sloan, ed., Valuing Health Care: Costs, Benefits, and Effectiveness of Pharmaceuticals and Other Medical Technologies, Cambridge: Cambridge University Press.

Whitlock, P., P. Michael, G. Carla, O. Tracy and K. Jonathan. 2004. "Behavioral Counseling Interventions in Primary Care To Reduce Risky/Harmful Alcohol Use by Adults: A Summary of the Evidence for the U.S. Preventive Services Task Force” Annals of Internal Medicine, 140(7):557-568.

Wooldridge, J. Econometric Analyses of Cross-Section and Panel Data, MIT Press, Cambridge, 2001. 
Young, J. M. and J. E. Ward. 1998. "Influence of physician and patient gender on provision of smoking cessation advice in general practice.” Tobacco Control, 7:360-363.

Zweifel, P. and G. Manning. 2000. "Moral Hazard and Consumer Incentives in Health Care." in A. J. Culyer and J. P. Newhouse, (eds.) Handbook of health economic, North-Holland. 
Table 1

Descriptive Statistics for Respondents Prior to Age 65

Health and Retirement Study: Waves 1-8

\begin{tabular}{|c|c|c|c|}
\hline Variable Name & Definition & Insured & Uninsured \\
\hline Age & Age in year & 61.807 & 61.926 \\
\hline Male & Dichotomous indicator for whether respondent is male & 0.454 & 0.412 \\
\hline White & Dichotomous indicator for whether respondent is white & 0.772 & 0.752 \\
\hline Black & Dichotomous indicator for whether respondent is black & $0.167 *$ & 0.138 \\
\hline Other Race & Dichotomous indicator for whether respondent is of some other race & $0.061 * * *$ & 0.110 \\
\hline Hispanic & Dichotomous indicator for whether respondent is Hispanic & $0.192 * * *$ & 0.404 \\
\hline Married & Dichotomous indicator for whether respondent is married & $0.685 * * *$ & 0.571 \\
\hline Divorced & Dichotomous indicator for whether respondent is divorced & 0.139 & 0.131 \\
\hline Full-time Employment & Dichotomous indicator for whether respondent works full-time & 0.332 & 0.321 \\
\hline Part-time Employment & Dichotomous indicator for whether respondent works part-time & $0.080^{*}$ & 0.115 \\
\hline Retirement & Dichotomous indicator for whether respondent if fully retired & $0.345 * * *$ & 0.220 \\
\hline Partial Retirement & Dichotomous indicator for whether respondent if partially retired & $0.073 * *$ & 0.049 \\
\hline Unemployed & $\begin{array}{l}\text { Dichotomous indicator for whether respondent is unemployed and looking for } \\
\text { work }\end{array}$ & $0.012 * * *$ & 0.033 \\
\hline Household Size & Number of adults ages 18 and over who reside in the household & $2.530 * * *$ & 2.878 \\
\hline Parents alive & Number of parents who are currently alive & 0.276 & 0.290 \\
\hline Assets & Net household wealth in 1982-1984 dollars & $100909.800^{* * *}$ & 57803.510 \\
\hline Any Doctor Visit & $\begin{array}{l}\text { Dichotomous indicator for whether respondent visited a doctor, emergency room } \\
\text { or clinic since the last wave or in the past two years }\end{array}$ & $0.857 * * *$ & 0.663 \\
\hline Number of Doctor Visits & Number of visits to the doctor since the last wave or in the past two years & $7.793 * * *$ & 4.414 \\
\hline Any Hospital Stay & $\begin{array}{l}\text { Dichotomous indicator for whether respondent had any overnight hospital stay } \\
\text { since the last wave or in the past two years }\end{array}$ & $0.200 * * *$ & 0.097 \\
\hline $\begin{array}{l}\text { Engaged in Vigorous } \\
\text { Physical Activity }\end{array}$ & $\begin{array}{l}\text { Dichotomous indicator for whether respondent participated in vigorous physical } \\
\text { activity or sports three or more times a week }\end{array}$ & 0.355 & 0.386 \\
\hline Daily Cigarette & Dichotomous indicator for whether respondent smokes everyday & & \\
\hline Consumption & & $0.272 *$ & 0.323 \\
\hline Number of Cigarettes & Average number of cigarettes smoked daily (Ever Smokers) & $7.032 * * *$ & 12.008 \\
\hline Quit Cigarettes & Dichotomous indicator for whether respondent has quit smoking (Ever Smokers) & $0.585^{* * *}$ & 0.474 \\
\hline Daily Alcohol & Dichotomous indicator for whether respondent consumed alcohol everyday in the & & \\
\hline Consumption & past 3 months & 0.060 & 0.077 \\
\hline Alcohol Participation & Dichotomous indicator for whether respondent consumed alcohol in the past month & 0.276 & 0.237 \\
\hline Number of Observations & & 4,166 & 470 \\
\hline
\end{tabular}

Notes: Means are reported for the pre-age 65 sample. The HRS sample is 60-64 years of age with less than a high school education. The uninsured sample represents individuals who are consistently uninsured in all eight waves. All means are weighted by the sampling weight. Stars denote that the difference in the means across the insured and uninsured groups is significant as follows: * indicates $0.05<\mathrm{p}$-value $\leq 0.10, * *$ indicates $\mathrm{p}$-value $\leq 0.05$. The number of observations represents the maximum sample size for the pre-age 65 group with non-missing information on doctor visits. For some variables, the sample size is less due to further missing observations (see text). 
Table 2

Estimates of the Effect of Receipt of Medicare at Age 65 on Doctor Visits and Hospital Stay Longitudinal Analysis Using Data from the Health and Retirement Study

DD:

Uninsured*Post 65

(Always Uninsured)

Uninsured*Age 63-64

\section{DDD:}

Uninsured*Post65 -

Uninsured*Age 63-64

DD:

Uninsured*Post 65

(Uninsured $>50 \%$ of Time)

Uninsured*Age 63-64

DDD:

Uninsured*Post65 -

Uninsured*Age 63-64

Mean of Dep. Variable for

Previously Uninsured

Always

Mean of Dep. Variable for

Previously Uninsured $>50 \%$ of Time

\section{Males}

Any Number of

Doctor Visit Doctor Visits

$0.080^{*}$
$(0.045)$
0.004
$(0.046)$

$0.076^{*}$
$(0.042)$

$0.084^{* *}$
$(0.036)$
0.010
$(0.035)$

$0.073 * *$

(0.035)

0.615

0.601

$$
\begin{gathered}
0.532 * * * \\
(0.169) \\
0.223 \\
(0.181)
\end{gathered}
$$

$0.309^{* *}$

$(0.137)$

$0.552^{* * *}$
$(0.130)$
$0.238^{*}$
$(0.131)$

$(0.131)$

$0.314 * * *$

(0.111)

5.013

4.414
Any

Hospital Stay

0.075
$(0.055)$
0.027
$(0.055)$

$(0.055)$

0.048

$(0.051)$

0.037

(0.043)

$-0.007$

(0.042)

0.045

$(0.042)$

0.149

0.128
Females

Number of

Doctor Visits

Any Hospital Stay

$0.315^{* *}$
$(0.118)$
-0.073

(0.119)

0.059

(0.046)

(0.033)

-0.043
$(0.033)$

0.026

(0.046)

0.027

(0.031)

$0.388^{* * *}$

(0.105)

0.032

(0.043)

$0.276^{* * *}$

(0.087)

0.002

(0.088)

0.010

(0.035)

0.011

0.006
$(0.025)$

(0.034)

$0.274 * * *$

$-0.001$

$0.049 * *$

(0.024)

(0.081)

(0.034)

0.787

7.308

0.150

7.564

Notes: OLS is used to obtain parameter estimates when dependent variable is any doctor or any hospital visit. For number of doctor visits, Poisson regression method is used. All models include controls for person-specific fixed effect, age (single year age dummy variables), marital status (two dummy variables: married and divorced), employment

(indicators for full-time, part-time, full retirement, partial retirement, unemployed), household size, number of living parents, assets, total years worked and year dummy variables.

$*$ indicates $0.05<$ p-value $\leq 0.10, * *$ indicates p-value $\leq 0.05$ 
Table 3

Estimates of the Effect of Receipt of Medicare at Age 65 on Health Behaviors

Longitudinal Analysis Using Data from the Health and Retirement Study

Male Sample

\section{Engaged in Vigorous \\ Physical Activity}

\section{Number of Cigarettes}

Daily

$\begin{array}{cccc}-0.067 & -0.123 & 0.007 & 0.290 \\ (0.071) & (0.132) & (0.150) & (0.223) \\ 0.024 & 0.028 & 0.020 & 0.063 \\ (0.068) & (0.069) & (0.150) & (0.159) \\ & & & \\ -0.091 & -0.151 & -0.013 & 0.227 \\ (0.065) & (0.132) & (0.148) & (0.239) \\ & 0.002 & & -0.100 \\ & (0.037) & & (0.082) \\ & 0.079 & & 0.011 \\ & (0.095) & & (0.210) \\ & -0.045 & & 0.037 \\ & (0.060) & & (0.136) \\ & 0.041 & & -0.421 \\ & (0.147) & & (0.277) \\ 0.380 & 0.380 & 13.346 & 13.346\end{array}$

\section{Daily Cigarette \\ Consumption (Yes/No)}

DD:

Uninsured*Post 65

(Always Uninsured)

Uninsured*Age 63-64

DDD:

Uninsured*Post65 -

Uninsured*Age 63-64

Doctor Visit

Doctor*Uninsured

Doctor*Post 65

Doctor*Uninsured*Post 65

Mean of Dep. Variable for Previously Uninsured

$\begin{array}{ll}-0.035 & 0.028\end{array}$

$(0.028) \quad(0.048)$

$-0.047^{*}$

(0.028)

$-0.039$

(0.029)

0.012

(0.026)

0.067

$(0.049)$

$-0.032 * *$
$(0.014)$

0.025

$(0.040)$

0.022

$(0.023)$

$-0.084$

(0.055)

0.425

0.425
Quit Cigarettes
(Limited to Ever
Smokers)

$\begin{array}{cc}0.047 & -0.028 \\ (0.036) & (0.062) \\ 0.064 * & 0.053 \\ (0.036) & (0.037)\end{array}$

$(0.036) \quad(0.037)$

$-0.017$

$(0.033)$

$-0.081$

(0.062)

$(0.050)$

(0.070)

0.451
$0.031^{*}$

$(0.018)$

$-0.037$

$-0.017$

(0.030)

0.106

Alcohol Participation
(Yes/No)

$\begin{array}{ll}0.014 & 0.087\end{array}$

$(0.047)$

$-0.026$

(0.048)

$(0.082)$

$-0.029$

(0.048)

0.040

(0.044)

0.116

(0.083)

$-0.068 * * *$

(0.024)

0.140 **

(0.067)

0.030

(0.039)

$-0.113$

(0.093)

0.451

0.365

0.365
Daily Alcohol

Consumption (Yes/No)

$(0.040)$

$-0.055$

$-0.037$

$(0.066)$

$-0.058$

(0.039) (0.040)

$0.003 \quad 0.020$

$(0.033)$

$(0.061)$

0.006

(0.018)

$-0.055$

(0.058)

$-0.004$

$(0.029)$

$-0.017$

(0.071)

0.135

0.135

Notes: For number of cigarettes, Poisson regression method is used. For all other outcomes, OLS is used to obtain parameter estimates. All models include controls for personspecific fixed effect, age (single year age dummy variables), marital status (two dummy variables: married and divorced), employment (indicators for full-time, part-time, full retirement, partial retirement, unemployed), household size, number of living parents, assets, total years worked and year dummy variables. $*$ indicates $0.05<$ p-value $\leq 0.10, * *$ indicates p-value $\leq 0.05$ 
Table 4

Cross-Equation Estimates of the Average Effect of Receipt of Medicare at Age 65 on Unhealthy Behaviors

Seemingly Unrelated Regression

Male Sample

Outcomes

No Vigorous Physical Activity Alcohol Participation

DDD:

Uninsured*Post65 -

Uninsured*Age 63-64

$$
0.234^{* *}
$$

$(0.095)$
No Vigorous Physical Activity

Did Not Quit Cigarettes

Alcohol Participation

$$
\begin{gathered}
0.241 * * \\
(0.095)
\end{gathered}
$$$$
\text { [0.01] }
$$

No Vigorous Physical Activity

Daily Cigarette Consumption

Daily Alcohol Consumption

0.178

$(0.120)$

[0.14]
No Vigorous Physical Activity

Did Not Quit Cigarettes

Daily Alcohol Consumption

0.184

$(0.121)$

Notes: Models are jointly estimated using a seemingly unrelated regression framework, and control for doctor visits, as specified in equation (9). All outcomes are redefined as unhealthy behaviors and transformed into standard normal deviates (see text). Estimates of the average effect of Medicare receipt on the three unhealthy behaviors are presented. Standard errors are reported in parentheses, and associated p-values are reported in brackets. $*$ indicates $0.05<\mathrm{p}$-value $\leq 0.10, * *$ indicates $\mathrm{p}$ value $\leq 0.05$ 
Table 5

Estimates of the Effect of Receipt of Medicare at Age 65 on Health Behaviors Longitudinal Analysis Using Data from the Health and Retirement Study

Female Sample

DD

Uninsured*Post 65

(Always Uninsured)

Uninsured*Age 63-64

DDD:

Uninsured*Post65 -

Uninsured*Age 63-64

Doctor Visit

Doctor*Uninsured

Doctor*Post 65

Doctor*Uninsured*Post 65

Mean of Dep. Variable for Previously Uninsured

See notes to Table 3 .
Engaged in Vigorous Number of Cigarettes Physical Activity

\section{Daily Cigarette \\ Consumption}

(Yes/No)

$\begin{array}{cc}-0.132 * * & -0.219 \\ (0.064) & (0.166) \\ -0.104^{*} & -0.091 \\ (0.057) & (0.059) \\ & \\ -0.029 & -0.128 \\ (0.060) & (0.165) \\ & 0.076^{*} \\ & (0.041) \\ & -0.160^{*} \\ & (0.089) \\ & -0.058 \\ & (0.083) \\ & 0.119 \\ & (0.177)\end{array}$

0.297

0.297

$\begin{array}{cc}-0.025 & -0.224 \\ (0.160) & (0.376) \\ 0.089 & 0.085 \\ (0.154) & (0.155) \\ & \\ -0.114 & -0.309 \\ (0.168) & (0.385) \\ & 0.045 \\ & (0.110) \\ & -0.033 \\ & (0.235) \\ & -0.268 \\ & (0.189) \\ & 0.214 \\ & (0.409)\end{array}$

8.008
8.008

0.230
0.230
Quit Cigarettes

(Limited to Ever

Smokers)

$\begin{array}{cc}-0.010 & 0.025 \\ (0.024) & (0.059) \\ 0.006 & 0.003 \\ (0.024) & (0.024) \\ & \\ -0.016 & 0.022 \\ (0.023) & (0.059) \\ & -0.044 * * \\ & (0.017) \\ & 0.044 \\ & (0.038) \\ & -0.019 \\ & (0.029) \\ & -0.049 \\ & (0.064)\end{array}$

$0.044 \quad-0.030$

$(0.044) \quad(0.117)$

0.005

(0.045)

0.013

$(0.046)$

0.039

$(0.042)$

$-0.043$

$(0.117)$

$0.088 * * *$

$(0.028)$

$-0.095$

$(0.074)$

0.042

$(0.051)$

0.103

(0.124)

0.561

0.561

0.104

$(0.031)$

$-0.003$

$(0.031)$

0.003

$(0.029)$

$(0.076)$

$-0.036^{*}$

$(0.021)$

0.012

$(0.049)$

0.002

$(0.038)$

0.052

(0.081)

0.104
0.026

Daily Alcohol Consumption

(Yes/No)

$-0.017$ $0.017)$

$-0.015 \quad-0.013$

$(0.016) \quad(0.016)$

$\begin{array}{ll}-0.003 & 0.021\end{array}$

$(0.014) \quad(0.035)$

0.008

(0.011)

0.020

$(0.025)$

$-0.001$

$(0.018)$

$-0.033$

$(0.038)$

0.026 
Table 6

Cross-Equation Estimates of the Average Effect of Receipt of Medicare at Age 65 on Unhealthy Behaviors

Seemingly Unrelated Regression

Female Sample

Outcomes

No Vigorous Physical Activity

Daily Cigarette Consumption

Alcohol Participation

\author{
No Vigorous Physical Activity \\ Did Not Quit Cigarettes \\ Alcohol Participation
}

No Vigorous Physical Activity

Daily Cigarette Consumption

Daily Alcohol Consumption
No Vigorous Physical Activity

Did Not Quit Cigarettes

Daily Alcohol Consumption

$\begin{array}{cc}0.154 & 0.165 \\ (0.131) & (0.140) \\ {[0.24]} & {[0.238]}\end{array}$

0.165

0.238
DDD:

Uninsured*Post65 -

0.073

$(0.145)$

[0.62]
0.084
$(0.156)$

Notes: Models are jointly estimated using a seemingly unrelated regression framework, and control for doctor visits, as specified in equation (9). All outcomes are redefined as unhealthy behaviors and transformed into standard normal deviates (see text). Estimates of the average effect of Medicare receipt on the three unhealthy behaviors are presented. Standard errors are reported in parentheses, and associated p-values are reported in brackets. * indicates $0.05<\mathrm{p}$-value $\leq 0.10, * *$ indicates $\mathrm{p}$ value $\leq 0.05$ 
Appendix Table 1

Estimates of the Effect of Receipt of Medicare at Age 65 on Health Behaviors Male Sample from the Health and Retirement Study, Partially Uninsured Prior to Age 65

DD:

Uninsured*Post 65

(Uninsured $>50 \%$ of Time)

Uninsured*Age 63-64

DDD:

Uninsured*Post65-

Uninsured*Age 63-64

Doctor Visit

Doctor*Uninsured

Doctor*Post 65

Doctor*Uninsured*Post 65

Mean of Dep. Variable for

Previously Uninsured

See notes to Table 3 . $\begin{array}{cc}\text { Engaged in Vigorous } & \text { Number of Cigarettes } \\ \text { Physical Activity } & \text { Daily }\end{array}$

\section{Daily Cigarette \\ Consumption \\ (Yes/No)}

$\begin{array}{cccc}0.008 & -0.077 & 0.009 & 0.283 \\ (0.059) & (0.111) & (0.128) & (0.209) \\ 0.027 & 0.027 & -0.022 & -0.012 \\ (0.055) & (0.056) & (0.118) & 0.121 \\ & & & \\ -0.019 & -0.104 & 0.030 & 0.294 \\ (0.056) & (0.112) & (0.127) & (0.215) \\ & 0.013 & & -0.138 \\ & (0.040) & & (0.091) \\ & -0.021 & & 0.135 \\ & (0.077) & & (0.165) \\ & -0.060 & & 0.107 \\ & (0.066) & & (0.155) \\ & 0.108 & & -0.474^{*} \\ & (0.125) & & (0.250) \\ & & & \end{array}$

0.422

0.422

$-0.052 * *$
$(0.022)$
$-0.056 * *$

(0.022)

$(0.022)$

0.004

$(0.021)$

0.023

(0.042)

$-0.026^{*}$

$(0.015)$

0.001

$(0.030)$

0.011

$(0.025)$

$-0.031$

(0.046)

$11.584 \quad 11.584$

0.402

0.402

\section{Quit Cigarettes \\ (Limited to Ever Smokers)}

$-0.027$

$(0.041)$

$0.080^{* * *}$

$(0.029)$

$0.077 * * *$
$(0.028)$

0.051

$(0.053)$

$0.069^{* *}$

(0.028)

0.003

(0.028)

$-0.019$

(0.053)

0.024

(0.020)

$-0.016$

(0.038)

$-0.0003$

(0.032)

0.045

(0.060)

0.487

0.487
Alcohol Participation

(Yes/No)

\section{$-0.005$}

$(0.037)$

$-0.017$

(0.037)

$-0.0004$

$(0.070)$

$-0.015$

(0.037)

0.012

(0.036)

0.015

$(0.071)$

$-0.055^{* *}$

$(0.026)$

0.027

(0.051)

0.009

$(0.042)$

$-0.006$

(0.079)

0.406
Daily Alcohol

Consumption

(Yes/No)

$\begin{array}{ll}-0.041 \quad-0.034 \\ (0.030) & (0.054)\end{array}$

$(0.030) \quad(0.054)$

$-0.013-0.013$

$(0.028) \quad(0.028)$

$\begin{array}{ll}-0.028 & -0.021 \\ (0.026) & (0.052)\end{array}$

$(0.026) \quad(0.052)$

0.019

$(0.020)$

$-0.054$

$(0.040)$

$-0.014$

$(0.033)$

$-0.010$

$(0.058)$

0.137 
Appendix Table 2

Estimates of the Effect of Receipt of Medicare at Age 65 on Health Behaviors

Female Sample from the Health and Retirement Study, Partially Uninsured Prior to Age 65

DD:

Uninsured*Post 65
(Uninsured $>50 \%$ of Time)

Uninsured*Age 63-64

\section{DDD:}

Uninsured*Post65 -

Uninsured*Age 63-64

Doctor Visit

\section{Doctor*Uninsured}

\section{Doctor*Post 65}

Doctor*Uninsured*Post 65

Mean of Dep. Variable for

Previously Uninsured

\section{Engaged in Vigorous Number of Cigarettes Physical Activity \\ Daily}

$-0.112 * *$
$(0.051)$
-0.054
$(0.045)$
-0.058
$(0.050)$

$-0.348 * *$
$(0.145)$
-0.042

$(0.046) \quad(0.127)$

$-0.306^{* *} \quad 0.058$

$(0.146)$

$0.079 *$

$(0.048)$

$-0.083$

$(0.074)$

$-0.142$

$(0.091)$

$0.272 *$

(0.154)

0.309

0.309
0.050

(0.132)

$-0.008$

(0.138)

$-0.274$

(0.333)

$-0.009$

(0.129)

$-0.265$

(0.341)

0.053

(0.126)

$-0.062$

(0.202)

$-0.324$

(0.205)

0.364

(0.361)

6.365

6.365

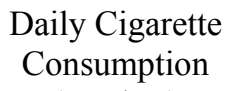

Consumption

(Yes/No)

$-0.010 \quad 0.044$

$(0.019) \quad(0.051)$

$-0.014 \quad-0.017$

$(0.018) \quad(0.018)$

$0.004 \quad 0.061$

(0.018)

$(0.051)$

$-0.056 * * *$
$(0.020)$

(0.031)

(0.054)

0.228

Smokers)

0.050

$-0.002$

(0.032)

$-0.067$

\section{Quit Cigarettes \\ (Limited to Ever \\ Smokers)}

$\begin{array}{cc}0.023 & -0.092 \\ (0.034) & (0.093)\end{array}$

$\begin{array}{ll}(0.034) & (0.093)\end{array}$

(0.033) (0.033)

$-0.004 \quad-0.124$

(0.033)

$(0.093)$
$0.119 * * *$

(0.033)

$-0.119^{* *}$

(0.053)

0.006

(0.057)

0.143

(0.099)

0.228

0.576

0.576
Alcohol Participation

(Yes/No)

$0.004 \quad-0.051$

$(0.024)$

0.008

(0.024)

$-0.004$

$(0.023)$

(1)

$(0.065)$

0.010

(0.024)

$-0.061$

(0.066)

$-0.004$

$(0.025)$

0.132

$-0.074 *$

(0.040)

$-0.013$

(0.042)

0.071

(0.070)

Daily Alcohol

Consumption

(Yes/No)

$\begin{array}{ll}-0.015 & 0.005\end{array}$

(0.012) (0.031)

$-0.005 \quad-0.005$

(0.012) (0.012)

$\begin{array}{ll}-0.009 & 0.010\end{array}$

(0.011) (0.031)

0.011

(0.013)

0.006

(0.019)

$-0.00002$

$(0.021)$

$-0.027$

(0.033)

0.132

0.015

See notes to Table 3. 


\section{Appendix A}

Alternative Dataset and Cross-Sectional Identification Approach

\section{Analytical Framework}

The second approach we use to obtain estimates of the effect of Medicare on health behaviors utilizes cross-sectional data on a sample of individuals aged 60 to 69 from the Behavioral Risk Factor Surveillance System (BRFSS). In this case, we exploit the fact that, among the elderly, some demographic groups are much more likely to be uninsured prior to age 65 than others. To simplify the exposition, we will refer to two groups: the uninsured, which are persons from demographic groups likely to be uninsured, and the insured, which are persons from demographic groups likely to have health insurance. Identification of the effect of Medicare comes from an analogous comparison to that used in the longitudinal analysis.

Basically, we compare the pre- to post-age 65 changes in health behaviors of a group likely to be uninsured to the pre- to post-age 65 changes in health behaviors of a group likely to be insured. The assumption underlying this research design is that in the absence of Medicare, changes preand post-age 65 in health behaviors would be the same for uninsured and insured persons. Thus, if we observe a change in the pre- and post-age 65 differences conditional on other covariates, we assume that it is due to Medicare.

The regression model to obtain the cross-sectional estimates of the effect of Medicare on health behaviors is given by:

$$
\begin{aligned}
& Y_{i t}=\alpha+\sum_{k=1}^{K} \beta_{k} X_{k i t}+\sum_{k=1}^{K} \eta_{k} Z_{k i t}+\sum_{t=1994}^{2005} \gamma_{t} Y E A R_{t}+\lambda_{1}\left(U \hat{N I N} N_{i} * \operatorname{POST~65~}_{t}\right) \\
& +\lambda_{2}\left(\text { UNIN }_{i} * \text { AGE63_64 }{ }_{t}\right)+\rho_{1} \text { DOCTOR }_{i t}+\rho_{2}\left(\text { DOCTOR }^{*}\right. \text { POST 65) } \\
& +\rho_{3}\left(\operatorname{UNIN}_{i} * \operatorname{DOCTOR}_{i t}\right)+\rho_{4}\left(\operatorname{UNIN}_{i} * \operatorname{DOCTOR}_{i t} * \operatorname{POST65}_{t}\right)+e_{i t} \text {. } \\
& i=1, \ldots, N \\
& t=1994, \ldots, 2005
\end{aligned}
$$


In equation (A1), all variables are defined as before except the following: $\mathrm{X}$ represents several demographic characteristics such as age, race, marital status and education that were subsumed by the individual fixed effects in the longitudinal analysis, interactions between these factors, and indicators for state of residence; $\mathrm{Z}$ represents other characteristics likely to vary over time for an individual, such as employment and household size; and UNIIN is a dummy variable indicating that the person has a relatively high probability of being uninsured prior to age 65 . Specifically, to construct the UNIN dummy variable, we first predict the probability that a person aged 60 to 64 is without health insurance using the following regression model estimated as a logit:

(A2) $U N I N_{i t}=\tau+\sum_{k=1}^{K} \phi_{k} X_{k i t}+\sum_{t=1994}^{2005} \sigma_{t} Y E A R_{t}+u_{i t}$.

Next, we assign persons to the uninsured and insured categories using the following rule:

$$
\begin{aligned}
& U \hat{N I N}=1 \quad \text { if } \quad\left(\hat{\tau}+\sum_{k=1}^{K} \hat{\phi}_{k} X_{k i t}\right)>\mu \\
& U \hat{N I N}=0 \quad \text { if } \quad\left(\hat{\tau}+\sum_{k=1}^{K} \hat{\phi}_{k} X_{k i t}\right) \leq \mu
\end{aligned}
$$

where the symbol ${ }^{\wedge}$ is used to indicate a predicted value and $\mu$ is either the $50^{\text {th }}$ or the $75^{\text {th }}$ percentile of the propensity score; we assign someone to the uninsured category if they have a predicted probability (propensity score) of being uninsured that is greater than at the $50^{\text {th }}$ or $75^{\text {th }}$ percentiles alternately. Equation (A3) is simply a way to classify persons as more or less likely to be insured.

One advantage of the cross-sectional approach is that UNIN is clearly exogenous; it is simply a linear combination of pre-determined variables. However, the disadvantage is that UNIIN is an imperfect way to identify persons who were uninsured prior to age 65 . Thus, some 
people we assign to the uninsured category will actually have health insurance prior to age 65 and some who we assign to the insured category will not have insurance prior to age 65. For example, using the 0.75 ( $75^{\text {th }}$ percentile) cutoff, we find that only 20 percent of males between the ages of 60 and 64 assigned to the uninsured category were actually uninsured, and eight percent of males ages 60 to 64 assigned to the insured category were uninsured. This measurement error will result in attenuated (biased toward zero) estimates of the effect of uninsured (treatment on treated); the magnitude of the attenuation will be substantial, as the estimated effect will be approximately 12 percent $(1 / 8)$ the magnitude of the treatment on treated effect. The extent of attenuation is very similar using the alternative threshold of $0.5\left(50^{\text {th }}\right.$ percentile). Fortunately, the BRFSS has relatively large samples that will mitigate the importance of this bias.

\section{Data}

The BRFSS is a state-based system of health surveys coordinated by the Centers for Disease Control and Prevention to collect uniform information on risky behaviors, preventive practices, and health care access and usage. The interviews are of adults 18 years of age and older, and are based on a multi-stage stratified random sampling of telephone numbers. By 1994 all states and the District of Columbia were participating in the BRFSS. The present analysis thus utilizes data from the years 1994 through 2005, excluding 2002 and 2003 for which information on physician visits is not available. One advantage of the BRFSS is its large sample size. There are 356,112 adults interviewed in 2005 , for instance. The empirical models are restricted to adults between the ages of 60 and 69 , similar to the HRS. We drop the disabled from the analysis. Individuals with a college education or above are further excluded because this demographic group has a very low probability of being uninsured prior to age 65 . For 
instance, the rate of uninsured for college-graduated adults (between the ages of 60 and 64) is 4.5 percent, compared to 12.0 percent for those who did not finish college. The final sample size is 116,051 .

Like the HRS, the BRFSS has information on health insurance coverage, doctor visits and health behaviors. An indicator for being uninsured is defined if the respondent reports not having health insurance coverage from any public, private or other sources. The respondent is also asked "how long it has been since they last visited a doctor for a routine check-up." A dichotomous indicator for any doctor visit within the past 12 months is defined.

We focus on the same behaviors as in the HRS: exercise, smoking and drinking. We try to create a consistent set of measures across the two surveys. For exercise, we define an indicator for whether the respondent participates in vigorous exercise or physical activity. In the BRFSS, this is a survey-coded variable based on a series of questions probing participation in several activities and their frequency. This indicator refers to participation in any activity or activities that require rhythmic contraction of large muscle groups at 50 percent of functional capacity for 20 or more minutes, three or more times a week. This measure is chosen due to its consistency across the years in order to maximize sample size. Other measures have more missing observations, though the results are not qualitatively affected. This measure of vigorous exercise is also more specifically defined relative to the measure available in the HRS, reflected in a lower prevalence for both males and females in the BRFSS.

For cigarette use, the BRFSS does not consistently ask about the number of cigarettes consumed or frequency of use. As a result, we create a dichotomous indicator for whether the respondent currently smokes everyday, which combines both current smoking participation and a measure of frequency. An indicator is also defined for whether the respondent quit smoking in 
the past year. Drinking is measured by a continuous variable for the average number of drinks consumed daily. This variable is based on a consistent set of questions that ask the respondents how many days they consumed alcohol in the past month and the number of drinks that they consumed on such days. In addition, the number of days that alcohol was consumed in the past month, which captures drinking frequency, and the number of drinks consumed on occasion are also employed as separate outcome variables in the specifications. These measures are chosen in the BRFSS to ensure consistency and comparison with the HRS estimates. Other measures of exercise, alcohol consumption, and smoking yielded similar results qualitatively.

\section{Cross Sectional Analysis of BRFSS}

We now turn to the results from the alternative research design that uses cross sectional data. In this analysis, we compare changes in health behaviors pre- and post-age 65 for those more and less likely to be uninsured. We classify people into the more- and less-likely to be uninsured groups using demographic characteristics. As described above this results in what we will refer to as misclassification, as a relatively small proportion of persons who we classify as uninsured are in fact uninsured (20 percent) and some who we classify as insured are in fact uninsured (eight percent). This will result in a downward biased estimate of the effect of receipt of Medicare for those who were actually uninsured. We can calculate the implied effect of receipt of Medicare among the uninsured by using the extent of misclassification, which we know, to rescale estimates.

The first outcome is the probability of seeing a physician in the last year and estimates for this analysis are reported in Appendix Table 3. For both males and females, estimates indicate that for those likely to be uninsured prior to age 65 , there was a relative increase in the probability of visiting a physician post-age 65 . For males, estimates indicate that turning age 65 
is associated with between a 2.4 and 2.9 percentage point increase in the probability of seeing a physician depending on how we classify persons to the insured and uninsured group (whether we use the 0.5 or 0.75 threshold of propensity score). Misclassification of persons to the insured and uninsured group imply that estimates of the effect of Medicare are approximately seven to eight times the size of the estimates reported in Table 5. Adjusting for the extent of misclassification suggests that among those actually uninsured, the probability of seeing a physician increased by between 16.8 and 20.3 percentage points, or between 22 and 27 percent. The magnitudes of these estimates are generally similar to what we found in the longitudinal analysis and provide further documentation that Medicare receipt results in an increase in physician contacts that may affect health behaviors and confound estimates of the ex ante moral hazard effect. Similar estimates are found for women.

Appendix Table 4 presents the estimates of the effect of turning age 65 on the health behaviors of elderly men from the BRFSS. We discuss the DDD estimates. However, they are similar to the DD estimates and the estimates indicate no pre-age 65 differences in trend. Among those likely to be uninsured prior to age 65 , receipt of Medicare is associated with a 4.2 percentage point decrease in the probability of engaging in vigorous physical activity in past month for those who do not visit the doctor. Going to the doctor post-receipt of Medicare is associated with a significant 5.0 percentage point increase in the probability of engaging in vigorous physical activity for those who were previously uninsured. These results are similar in sign to the results from the analysis that used longitudinal data. However, adjusting the estimates for the attenuation bias due to misclassification, yields large effect sizes. Estimates, which use an alternative classification of persons to the insured and uninsured groups based on the $50^{\text {th }}$ percentile, are similar in sign to those in Appendix Table 4, although smaller in 
magnitude. It is important to note that estimates rescaled to account for misclassification can differ dramatically with relatively small changes in the underlying estimates.

The next outcome examined is cigarettes. Estimates indicate that receipt of Medicare is associated with a significant 1.9 percentage point decrease in the incidence of daily cigarette consumption before controlling for physician visits. Controlling for physician visits, Medicare is associated with a 1.4 percentage point increase in the incidence of daily cigarette consumption among those who do not visit the doctor, and visits to the doctor are associated with significant decreases in cigarette use. So here we again have evidence of an ex ante moral hazard effect. Among the previously uninsured who do not visit the doctor, rescaled estimates suggest that Medicare is associated with a 10 percentage point (47 percent) increase in the probability of being a daily smoker, which is somewhat larger than estimates from the longitudinal analysis. For those previously uninsured that go to the doctor, Medicare is associated with more beneficial effects, as doctor visits are associated with significant reductions in the prevalence of daily smoking. Similar results are found for the probability of quitting smoking, although the estimate of the ex ante moral hazard effect is not statistically significant. The rescaled estimate is large, however, indicating an 5.3 percentage point (110 percent) decrease in the probability of quitting cigarette use among those who never go to the doctor.

We also find evidence of an ex ante moral hazard effect for alcohol use. We measure alcohol use two ways: number of days drank in past month and number of drinks on days drank. In models that do not control for doctor visits, Medicare is associated with a decrease or very small increase in each measure of alcohol consumption. But when we control for doctor visits and identify the ex ante moral hazard effect from the effect of physicians, we find that the main effect of Medicare increases in magnitude, and that physician visits are associated with decreased 
alcohol use. None of the estimates of the ex ante moral hazard effect are statistically significant and rescaled estimates generally imply much larger effects, although estimates for an insurance classification based on the $50^{\text {th }}$ percentile suggest somewhat smaller ex ante moral hazard effects.

The last set of results is the cross-sectional estimates for women, which are presented in Appendix Table 5. In the case of exercise, estimates indicate that among those likely to be uninsured and who do not visit the doctor, the ex ante moral hazard effect of Medicare is a 2.1 percentage point decrease in the probability of vigorous exercise, which when scaled to account for the misclassification of persons into insured and uninsured groups imply that receipt of Medicare is associated with a 14.7 percentage point decrease in vigorous exercise. Physician visits also tend to increase exercise.

Estimates related to cigarette use indicate that Medicare is associated with a significant decrease in the probability of being a daily smoker before controlling for physician visits. However, almost all of this effect is due to the health promotion benefits of physician contact. The ex ante moral hazard effect is present, however, for smoking cessation; Medicare reduces the probability of quitting among previously uninsured individuals who do not visit the doctor.

As before, we find evidence of an ex ante moral hazard effect for alcohol use.

Controlling for doctor visits, receipt of Medicare is associated with an increase in the number of days that a woman drank in past month and the number of drinks on days she drank. While none of these estimates are statistically significant, they imply large effects given the misclassification bias. For example, monthly alcohol consumption is 10.5 percent higher after receipt of Medicare for those likely to be uninsured prior to age 65. Doctor visits also tend to reduce drinking and 
the evidence in support of an ex ante moral hazard effect is much stronger after we control for doctor visits. 
Appendix Table 3

Estimates of the Effect of Receipt of Medicare at Age 65 on Doctor Visits

Cross Sectional Analysis Using Data from the Behavioral Risk Factor Surveillance System

DD:

Predicted Uninsured *Post 65

(Prediction Based on 75 Percentile)

Uninsured*Age 63-64

DDD:

Uninsured*Post65 -

Uninsured*Age 63-64

DD:

Predicted Uninsured *Post 65

(Prediction Based on 50 Percentile)

Uninsured*Age 63-64

DDD:

Uninsured*Post65 -

Uninsured*Age 63-64

Mean of Dep. Variable for

Previously Uninsured

(Prediction Based on 75 Percentile)

Mean of Dep. Variable for

Previously Uninsured

(Prediction Based on 50 Percentile)

$\begin{array}{cc}\text { Males } & \text { Females } \\ \text { Any } & \text { Any } \\ \text { Doctor Visit } & \text { Doctor Visit }\end{array}$

$0.031 * * \quad 0.030^{* *}$

$(0.011) \quad(0.008)$

$0.002 \quad 0.016$

$(0.014) \quad(0.010)$

$0.029 * * \quad 0.015 *$

(0.013) (0.009)

$0.027^{* *} \quad 0.016^{* *}$

$(0.010) \quad(0.007)$

$0.003 \quad 0.013$

$(0.012) \quad(0.009)$

$0.024 * * \quad 0.004$

$(0.011) \quad(0.008)$

$\begin{array}{ll}0.725 & 0.812\end{array}$

$\begin{array}{ll}0.756 & 0.813\end{array}$

Notes: Standard errors are reported in parentheses. All models include controls the propensity score, age (singleyear age dummy variables), employment (indicators for working for pay, self-employed, unemployed, homemaker or student, and retired), household size, and year dummy variables. $*$ indicates $0.05<$ p-value $\leq 0.10, * *$ indicates p-value $\leq 0.05$ 
Appendix Table 4

Estimates of the Effect of Receipt of Medicare at Age 65 on Health Behaviors

Cross Sectional Analysis Using Data from the Behavioral Risk Factor Surveillance System Predicted Uninsured Based on $75^{\text {th }}$ Percentile of Propensity Score

Male Sample

\begin{tabular}{|c|c|c|c|c|c|c|c|c|c|c|}
\hline \multirow{3}{*}{$\begin{array}{l}\text { DD: } \\
\text { Predicted Uninsured*Post } 65 \\
\text { Uninsured*Age } 63-64\end{array}$} & \multicolumn{2}{|c|}{$\begin{array}{l}\text { Engaged in Vigorous } \\
\text { Physical Activity }\end{array}$} & \multicolumn{2}{|c|}{$\begin{array}{c}\text { Daily Cigarette } \\
\text { Consumption (Yes/No) }\end{array}$} & \multicolumn{2}{|c|}{$\begin{array}{l}\text { Quit Cigarettes } \\
\text { Past Year } \\
\text { (Limited to Ever } \\
\text { Smokers) }\end{array}$} & \multicolumn{2}{|c|}{$\begin{array}{l}\text { Number of Days Drink } \\
\text { Past Month }\end{array}$} & \multicolumn{2}{|c|}{$\begin{array}{l}\text { Average Drinks on } \\
\text { Occasion }\end{array}$} \\
\hline & $\begin{array}{l}-0.010 \\
(0.011)\end{array}$ & $\begin{array}{c}-0.046^{* *} \\
(0.019)\end{array}$ & $\begin{array}{l}-0.019^{*} \\
(0.010)\end{array}$ & $\begin{array}{c}0.014 \\
(0.017)\end{array}$ & $\begin{array}{r}-0.0004 \\
(0.005)\end{array}$ & $\begin{array}{l}-0.008 \\
(0.009)\end{array}$ & $\begin{array}{c}-0.111^{*} \\
(0.058)\end{array}$ & $\begin{array}{c}0.015 \\
(0.093)\end{array}$ & $\begin{array}{r}-0.101 * \\
(0.053)\end{array}$ & $\begin{array}{l}-0.014 \\
(0.092)\end{array}$ \\
\hline & $\begin{array}{l}-0.005 \\
(0.014)\end{array}$ & $\begin{array}{l}-0.003 \\
(0.014)\end{array}$ & $\begin{array}{l}0.0004 \\
(0.012)\end{array}$ & $\begin{array}{l}0.0005 \\
(0.012)\end{array}$ & $\begin{array}{l}-0.001 \\
(0.007)\end{array}$ & $\begin{array}{l}-0.001 \\
(0.007)\end{array}$ & $\begin{array}{r}-0.131^{*} \\
(0.074)\end{array}$ & $\begin{array}{l}-0.127^{*} \\
(0.074)\end{array}$ & $\begin{array}{l}-0.045 \\
(0.069)\end{array}$ & $\begin{array}{l}-0.041 \\
(0.069)\end{array}$ \\
\hline $\begin{array}{l}\text { DDD: } \\
\text { Uninsured*Post65 - }\end{array}$ & -0.006 & $-0.042 * *$ & $-0.019^{*}$ & 0.014 & 0.001 & -0.007 & 0.020 & 0.142 & -0.056 & 0.027 \\
\hline Uninsured*Age 63-64 & $(0.012)$ & $(0.020)$ & $(0.011)$ & $(0.018)$ & $(0.006)$ & $(0.010)$ & $(0.069)$ & $(0.102)$ & $(0.066)$ & $(0.098)$ \\
\hline Doctor Visit & & $\begin{array}{l}0.017 * * \\
(0.008)\end{array}$ & & $\begin{array}{c}-0.082 * * \\
(0.007)\end{array}$ & & $\begin{array}{c}0.006 \\
(0.004)\end{array}$ & & $\begin{array}{c}-0.157 * * \\
(0.036)\end{array}$ & & $\begin{array}{c}-0.124 * * \\
(0.033)\end{array}$ \\
\hline Doctor*Uninsured & & $\begin{array}{c}-0.032 * * \\
(0.015)\end{array}$ & & $\begin{array}{l}-0.001 \\
(0.013)\end{array}$ & & $\begin{array}{c}0.004 \\
(0.007)\end{array}$ & & $\begin{array}{c}-0.160 * * \\
(0.074)\end{array}$ & & $\begin{array}{c}-0.160 * * \\
(0.069)\end{array}$ \\
\hline Doctor*Post 65 & & $\begin{array}{l}-0.010 \\
(0.011)\end{array}$ & & $\begin{array}{c}0.023^{* *} \\
(0.010)\end{array}$ & & $\begin{array}{l}0.0004 \\
(0.006)\end{array}$ & & $\begin{array}{l}0.113^{* *} \\
(0.055)\end{array}$ & & $\begin{array}{l}-0.003 \\
(0.050)\end{array}$ \\
\hline Doctor*Uninsured*Post 65 & & $\begin{array}{c}0.050^{* *} \\
(0.021)\end{array}$ & & $\begin{array}{c}-0.039 * * \\
(0.019)\end{array}$ & & $\begin{array}{c}0.010 \\
(0.010)\end{array}$ & & $\begin{array}{l}-0.139 \\
(0.110)\end{array}$ & & $\begin{array}{l}-0.101 \\
(0.105)\end{array}$ \\
\hline $\begin{array}{l}\text { Mean of Dep. Variable for } \\
\text { Previously Uninsured }\end{array}$ & 0.110 & 0.110 & 0.212 & 0.212 & 0.048 & 0.048 & 4.360 & 4.360 & 1.039 & 1.039 \\
\hline
\end{tabular}

Notes: For number of days drink and number of alcohol drinks, Poisson regression method is used with robust-corrected standard errors. Otherwise, OLS is used. Standard errors are reported in parentheses. All models include controls for the propensity score, age (single-year age dummy variables), employment (indicators for working for pay, selfemployed, unemployed, homemaker or student, and retired), household size, and year dummy variables. $*$ indicates $0.05<\mathrm{p}$-value $\leq 0.10, * *$ indicates $\mathrm{p}$-value $\leq 0.05$ 
Appendix Table 5

Estimates of the Effect of Receipt of Medicare at Age 65 on Health Behaviors

Cross Sectional Analysis Using Data from the Behavioral Risk Factor Surveillance System Predicted Uninsured Based on $75^{\text {th }}$ Percentile of Propensity Score

Female Sample

Engaged in Vigorous
Physical Activity

DD:

Predicted Uninsured*Post 65

Uninsured*Age 63-64

\section{DDD:}

Uninsured*Post65 -

Uninsured*Age 63-64

Doctor Visit

Doctor*Uninsured

\section{Doctor*Post 65}

Doctor*Uninsured*Post 65

Mean of Dep. Variable for

Previously Uninsured

See notes to Appendix Table 5.

0.094

0.094
Daily Cigarette

Consumption (Yes/No)

$\begin{array}{cc}-0.002 & -0.016 \\ (0.008) & (0.015) \\ 0.005 & 0.005 \\ (0.010) & (0.010) \\ & \\ -0.007 & -0.021 \\ (0.009) & (0.016) \\ & 0.021^{* *} \\ & (0.006) \\ & -0.029^{* *} \\ & (0.012) \\ & -0.010 \\ & (0.009) \\ & 0.019 \\ & (0.017)\end{array}$

0.163

$-0.021 * *$

$(0.007)$

$-0.008$

(0.009)

$-0.014^{*}$

(0.008)

(1)

(Yes/No)

Quit Cigarettes
Past Year

(Limited to Ever

$$
\text { Smokers) }
$$

$0.001 \quad-0.013$

$(0.005) \quad(0.010)$

$0.001 \quad 0.001$

$-0.006$

(0.009)

(0.007)

(0.007)

0.003

(0.014)

$-0.089 * *$

$(0.005)$
-0.015

(0.010)

$0.032 * *$

$(0.008)$

$-0.017$

(0.014)

$-0.00002$

(0.006)

$-0.013$

(0.011)

$0.013 * *$

(0.004)

0.001

$(0.008)$

$-0.001$

$(0.006)$

0.016

(0.011)

0.163

0.062

0.062

1.285

$-0.039$

(0.076)

0.0003

(0.098)

$-0.039$

(0.088)

Past Month
Past Days

Average Drinks on

Occasion

$-0.104 *$

$(0.054) \quad(0.098)$

$-0.028 \quad-0.025$

(0.072) (0.072)

$\begin{array}{ll}-0.076 & 0.022\end{array}$

$\begin{array}{ccc}(0.144) & (0.066) & (0.105) \\ -0.074 * & & -0.033\end{array}$

$(0.042)$

$-0.171$

(0.107)

$-0.017$

(0.062)

$-0.059$

(0.150)

(0.030)

$-0.167 * *$

(0.078)

$-0.043$

(0.044)

$-0.118$

(0.109)

1.285

0.349

0.349 